\title{
A bulge structure in HIV-1 TAR RNA is required for Tat binding and Tat- mediated trans-activation
}

\author{
Sophie Roy, ${ }^{1}$ Ulrike Delling, ${ }^{1}$ Chein-Hwa Chen, ${ }^{2}$ Craig A. Rosen, ${ }^{2}$ and Nahum Sonenberg, ${ }^{1,3,4}$ \\ ${ }^{1}$ Department of Biochemistry and ${ }^{3}$ McGill Cancer Center, McGill University, Montreal, Quebec, H3G 1Y6 Canada; \\ ${ }^{2}$ Department of Molecular Oncology and Virology, Roche Institute of Molecular Biology, Roche Research Center, Nutley, \\ New Jersey 07110 USA
}

\begin{abstract}
The Tat protein of human immunodeficiency virus type 1 (HIV-1) trans-activates viral gene expression and is obligatory for virus replication. Tat function is mediated through a sequence termed TAR that comprises part of the 5'-noncoding region of all HIV-1 mRNAs. This region forms a stable stem-loop structure in vitro. Recent evidence indicates that Tat binds directly to the TAR RNA sequence, and this binding is independent of the nucleotide sequence in the loop but dependent on the integrity of the upper stem. We used the electrophoretic mobility-shift assay to identify the sequence and structure specificity of this interaction and its correlation with Tat trans-activation. We show that a 3-nucleotide bulge structure (positions +23 to +25 ) in TAR RNA is important for both Tat interaction with TAR RNA and Tat-mediated trans-activation of gene expression. Single base substitutions at position +23 that impair Tat-mediated trans-activation in vivo also reduce binding of Tat to TAR in vitro, suggesting that the first uridine residue in the bulge is the critical base for both functions. In contrast, mutations in the loop (positions +31 to +34 ) and the stem (positions +9 to +12 and +49 to +52 ), which reduce Tat-mediated trans-activation, had no effect on Tat binding. We also show that a Tat peptide that includes the basic region required for nucleolar localization binds to TAR RNA with the same specificity as the full-length protein. We conclude that Tat binding to TAR is necessary but not sufficient by itself to account for trans-activation.
\end{abstract}

[Key Words: HIV-1; Tat protein; TAR RNA; trans-activation]

Received May 14, 1990; revised version accepted June 18, 1990.

The trans-acting factor Tat of the human immunodeficiency virus type 1 (HIV-1) acts via a sequence (termed TAR/ mapped between nucleotides -17 and +80 of the HIV-1 LTR (Rosen et al. 1985) to stimulate viral gene expression. The tat gene product is necessary for viral replication (Dayton et al. 1986; Fisher et al. 1986). Several mechanisms have been proposed to explain its action, including enhancement of HIV-1 LTR-directed transcription rate (Jakobovits et al. 1988; Jeang et al. 1988; Rice and Mathews 1988; Laspia et al. 1989), increase in mRNA stability (Muesing et al. 1987), anti-termination of transcription within the $\mathrm{R}$ region of the LTR (Kao et al. 1987; Selby et al. 1989; Toohey and Jones 1989), and enhancement of translation of HIV-1 mRNAs (Rosen et al. 1986a; Feinberg et al. 1986; Braddock et al. 1989). Bimodal mechanisms involving transcriptional and post-transcriptional events have also been suggested (Cullen 1986; Wright et al. 1986; Sadaie et al. 1988).

Although the mechanism of action of Tat remains moot, increasing evidence suggests that the TAR element is recognized as RNA (Feng and Holland 1988;

${ }^{4}$ Corresponding author.
Berkhout et al. 1989). The RNA comprising the TAR region assumes a stable stem-loop structure in vitro, as determined by RNA nuclease mapping (Muesing et al. 1987). Extensive mutational analysis of TAR has identified primary sequence as well as secondary structure requirements for Tat-mediated trans-activation. The most critical region comprises nucleotides +18 to +44 (Feng and Holland 1988; Hauber and Cullen 1988; Jakobovits et al. 1988; Garcia et al. 1989; Selby et al. 1989; Roy et al. 1990), although sequences extending to nucleotide +52 are required for the full magnitude of the trans-activation response (Roy et al. 1990). Important features for trans-activation in this region include the primary sequence in the loop, the 3-nucleotide bulge at position +23 to +25 (which will be referred to in the text as the bulge), and an intact stem. Hence, it is likely that transacting factors involved in Tat-mediated trans-activation bind to the loop and the bulge in a sequence-specific fashion and that the integrity of the stem is necessary for the maintenance of the bulge and the loop in the proper conformation for recognition by these factors. In agreement with this hypothesis, several TAR RNA-binding proteins have been identified in HeLa and CV-1 cell nuclear extracts by RNA mobility shift and UV-induced 
cross-linking assays (Gatignol et al. 1989; Gaynor et al. 1989; Marciniak et al. 1990). The loop region and the stem structure were found to contribute to the stability of these interactions (Gaynor et al. 1989; Marciniak et al. 1990). Binding of these trans-acting factors to TAR RNA was independent of Tat. Structural features within the TAR stem-loop necessary for binding in vitro were also required for Tat function in vivo, suggesting that these nucleoprotein interactions bear relevance to the mechanism of trans-activation. More recently, purified Tat protein was reported to bind to TAR RNA but not to TAR DNA in vitro, as determined by RNA mobility shift, filter binding, and immunoprecipitation assays (Dingwall et al. 1989). This interaction required intact base-pairing proximal to the loop but was independent of the sequence in the loop.

In this study, we identified distinct structural features within the TAR region that are required for both Tatmediated trans-activation and Tat binding. These include the uridine residue at position +23 in the bulge as well as the integrity of the stem in its vicinity. Specific binding to TAR RNA is also observed with a Tat peptide containing the basic domain of the protein. Our results indicate that nucleoprotein complex formation between Tat and TAR RNA is necessary but not sufficient for trans-activation of HIV-1 gene expression.

\section{Results}

\section{Tat binds to TAR RNA}

An RNA mobilit-shift assay was used to characterize the binding of Tat to TAR RNA. These studies required a highly purified source of Tat protein. A recombinant Tat protein containing a stretch of six histidine residues was engineered, overexpressed in Escherichia coli, and purified to $>95 \%$ homogeneity in a single step by immobilized metal ion chromatography with a resin selective for proteins with neighboring histidine residues. This purification scheme was shown previously to yield Tat protein that retained trans-activation activity (Gentz et al. 1989). The purity of the protein preparation was verified by SDS-polyacrylamide gel electrophoresis followed by silver staining (data not shown).

Purified wild-type Tat was mixed with ${ }^{32} \mathrm{P}$-labeled RNA synthesized in vitro by SP6 polymerase from the pSP64TARCAT plasmid (Parkin et al. 1988), which had been digested with HindIII (at nucleotide +80 of the HIV-1 TAR sequence). This construct generates RNA that begins at nucleotide +1 of the HIV-1 LTR and thus has the same nucleotide sequence at its $5^{\prime}$ end as HIV-1 mRNAs synthesized in vivo. Nucleoprotein complexes were observed after resolution on a nondenaturing $5 \%$ polyacrylamide gel and autoradiography (Fig. 1, lane 2). To determine the specificity of the interaction between Tat and TAR RNA, competition assays were performed with excess ${ }^{3} \mathrm{H}$-labeled transcripts. Complex formation was reduced $\sim 7$-fold in the presence of a 10-fold molar excess of competitor (Fig. 1, lane 3) and was barely detectable in the presence of 50- and 100-fold molar excess competitor (lanes 4 and 5). In contrast, an oligodeoxynucleotide comprising nucleotides +1 to +59 of the TAR region had no effect on the formation of Tat-TAR RNA complexes, even when added at a 500-fold molar excess (lanes 6-9). Moreover, 10- to 100-fold excess tRNA did not prevent Tat binding to TAR RNA (lanes 10-12); complex formation was reduced by only 7 -fold in the presence of a vast molar excess of tRNA (500-fold; lane 13).

To determine the affinity constant of the interaction between Tat and TAR RNA, the RNA mobility-shift assay was performed with $0.4 \mu \mathrm{M}$ (100 $\mathrm{ng}$ ) of protein using 0.15 to $2.5 \mathrm{nM}$ radiolabeled RNA. The amounts of protein-bound and free RNA were quantitated by laser densitometric scanning of the autoradiograph, and the affinity constant and concentration of binding sites on the protein were obtained by Scatchard-type analysis (Fig. 2) (Haile et al. 1989). The $K_{\mathrm{d}}$ of the interaction, derived from the intercept on the abscissa, was $1.4 \times 10^{-10} \mathrm{M}$, indicating that Tat binds to TAR RNA with high affinity. The concentration of binding sites, derived from the reciprocal of the slope, was $0.4 \mathrm{~nm}$. This number is $\sim 1000$ times less than the concentration of Tat protein used $(0.4 \mu \mathrm{M})$, suggesting that only a fraction of the purified protein was active in this assay. Alternatively, protein aggregates may be present, thus rendering many binding sites nonaccessible.

To rule out the possibility that minor Escherichia coli contaminants in the protein preparation are responsible for the mobility shift, anti-Tat monoclonal antibodies were added to the reaction mixtures. Nucleoprotein complex formation was abolished in the presence of three different monoclonal antibodies to Tat (Fig. 3, lanes $3-5$ ), but was not affected by monoclonal anti-

Figure 1. Electrophoretic mobility-shift analysis of Tat binding to TAR RNA: effect of competitors. One-hundred nanograms (ng) of purified Tat was preincubated in the absence (lane 2) or presence of excess ${ }^{3} \mathrm{H}$-labeled TAR RNA (lanes 3-5), TAR DNA (a 59-mer comprising HIV-1 nucleotides +1 to +59; lanes 6-9), or calf liver tRNA (lanes 10-13), prior to the addition of ${ }^{32} \mathrm{P}$-labeled TAR RNA. Complexes were resolved on a nondenaturing polyacrylamide gel, as described in Experimental procedures. (Lane 1) Free RNA.

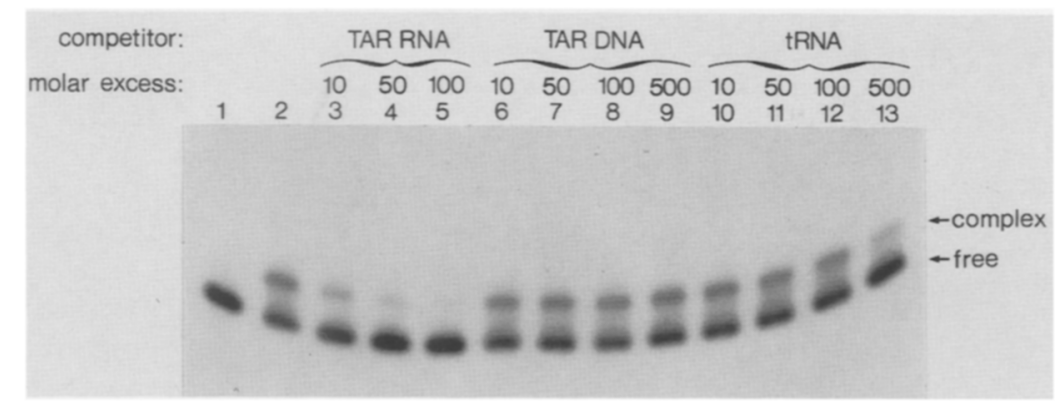




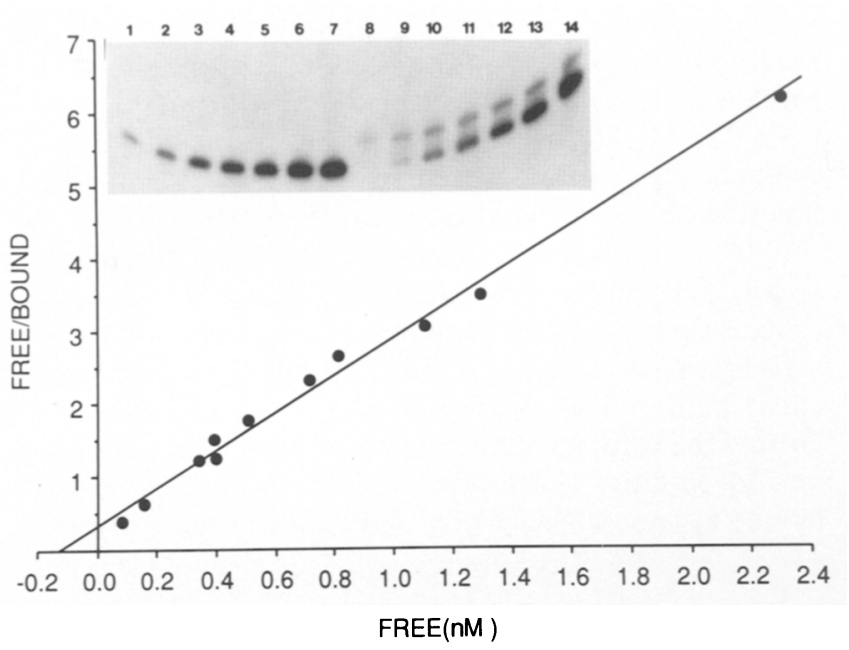

Figure 2. Scatchard-type analysis of Tat binding to TAR RNA. A plot of free/bound versus free RNA at different RNA concentrations and a representative RNA mobility- shift assay used for this analysis are shown. Increasing amounts of RNA $0.2-2.5$ $\mathrm{nM})$ were incubated with wild-type Tat protein $(0.4 \mu \mathrm{M} ; 100 \mathrm{ng})$. RNA-protein complexes were resolved on a nondenaturing polyacrylamide gel, and the gel was processed for autoradiography, as described in Experimental procedures. The amount of protein-bound and free RNA was quantitated by laser densitometric scanning of the autoradiograph. Known amounts of RNA (lanes 1-7) were subjected to electrophoresis in parallel with the RNA-protein complexes (lanes 8-14) to provide a standard curve for quantitation of RNA. Quantitation of the autoradiographs following exposure times, which were in the linear range was performed. The slope of the plot defines the reciprocal of the concentration of binding sites, whereas the intercept at the abscissa defines the $K_{\mathrm{d}}$.

bodies to the HIV-1 Rev protein (lanes 6 and 7). Furthermore, chemically synthesized Tat peptides generated a gel mobility shift similar to that of the Escherichia coli recombinant Tat protein (see below). Taken together, these results prove that Tat itself, and not a contaminant, complexes with TAR RNA to cause a shift in the mobility of the RNA. Anti-Tat monoclonal antibodies failed to cause a "super-shift" of Tat-TAR RNA com-

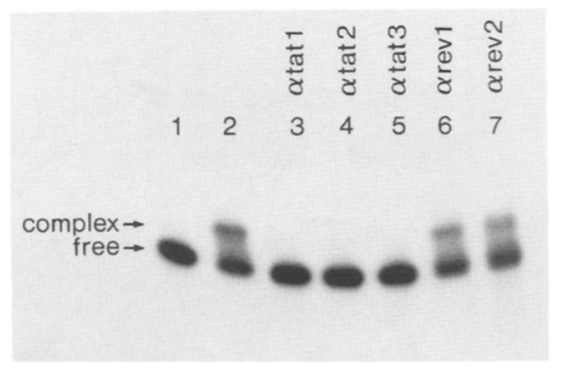

Figure 3. Effect of anti-Tat monoclonal antibodies on Tat binding to TAR RNA. One hundred ng of purified Tat was preincubated in the absence (lane 2) or presence of $1 \mu \mathrm{g}$ of different monoclonal antibodies to Tat (lanes 3-5) or Rev (lanes 6 and 7), prior to the addition of ${ }^{32} \mathrm{P}$-labeled TAR RNA. Complexes were resolved on a nondenaturing polyacrylamide gel, as described in Experimental procedures. (Lane 1) Free RNA. plexes, even when added after the complexes were formed (data not shown), suggesting that these antibodies recognize regions in Tat required for binding to TAR RNA.

\section{The primary sequence in the bulge is critical for Tat binding}

Deletion of the bulge in the TAR region was shown previously to reduce trans-activation to various degrees, depending on the transfection system used ( 7-fold, Berkhout and Jeang 1989 ; 300 -fold, Roy et al. 1990). We repeated this experiment and obtained results comparable to our own previously reported results (Roy et al. 1990; Fig. 5B, lanes 3 and 4). In addition, bulged nucleotides within RNA stem loop structures have been proposed to be sites for protein binding (Peattie et al. 1981; Wickens and Dahlberg 1987). In view of these results, a mutant TAR RNA with a deleted bulge ( $\Delta \mathrm{B} ;$ Fig. 4$)$ was tested in the RNA mobility-shift assay for nucleoprotein complex formation with Tat. Deletion of the bulge resulted in the loss of Tat binding (some minor diffusion of the RNA was apparent in the presence of protein; Fig. 5A, cf. lanes 4 and 3). These results pointed to the bulge as a key element for Tat binding and trans-activation. Consequently, mutational analysis of the bulge was carried out to define the sequence within the bulge required for both trans-activation in vivo and Tat binding in vitro. The different mutations are shown in Figure 4. TAR function was tested by transient transfection of the plasmid pU3RIII [Sodroski et al. 1985; this plasmid contains the CAT reporter gene under the control of the HIV-1 LTR ( -167 to +83$))$, into a HeLa cell line stably expressing tat (Roy et al. 1990). We introduced mutations in the UCU bulge to change one nucleotide (ACU,
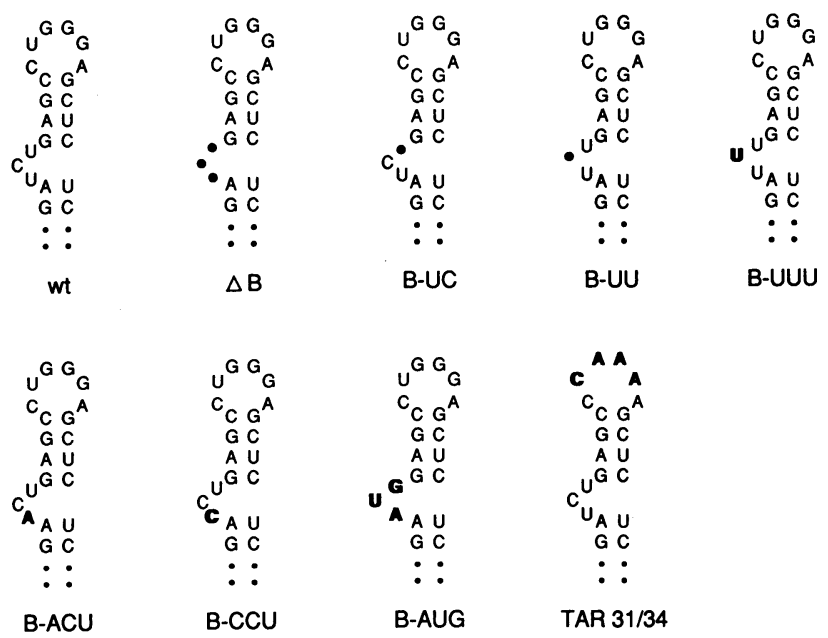

Figure 4. Bulge and loop mutations in the TAR region. Nucleotides +21 to +41 of wild-type or mutated TAR sequences and their predicted secondary structures are shown. Base substitutions are indicated in boldface; $(0)$ deleted nucleotides. Mutations were introduced by site-directed mutagenesis as described in Experimental procedures and subcloned into pU3RIII for transfection experiments or pSP64TARCAT to generate RNA for binding studies. 
$\mathrm{CCU}$ ) or all three nucleotides (AUG). In addition, we mutated the bulge into sequences that occur in nature: UC (in HIV- $1_{\text {MAL }}$ ), UU (in HIV-2 and SIV), and UUU (in HIV-1 $1_{\mathrm{BRU}}, \mathrm{HIV}-1_{\mathrm{EL}} \mathrm{HIV}-1_{\mathrm{Z6} 6}$, and HIV-1 $1_{\mathrm{zzZ}}$ ) (Myers 1989|. A 1-nucleotide substitution in the bulge (UCU to ACU or CCU) diminished TAR function 25-fold (Fig. 5B, lanes 5 and 6, 7 and 8). Substitution of all three nucleotides (UCU to AUG) decreased Tat-mediated trans-activation 10-fold (Fig. 5B, lanes 9 and 10; we have not examined possible positive effects on the translation of the CAT gene that result from the introduction of the upstream AUG). The corresponding RNAs, tested in the mobility-shift assay with Tat, failed to form nucleoprotein complexes (minor diffusion of the TAR RNA occurred in the presence of Tat; Fig. 5A, lanes 6, 8, and 10). Titration of the mutant RNAs $\triangle B, B-A C U, B-C C U$, B-AUG with increasing amounts of Tat (up to $400 \mathrm{ng}$ ) did not result in the formation of RNA-protein complexes (data not shown). We cannot exclude the possibility that highly unstable nucleoprotein complexes form in vivo, thus accounting for the residual trans-activation activity observed with mutants B-ACU, B-CCU, and B-AUG. In contrast, substituton of UU, UUU, or UC for the sequence UCU had no significant effect on trans- activation activity (Fig. 5B, lanes 11-16), and Tat binding to RNAs containing these mutations was comparable to that observed with wild-type RNA (Fig. 5A, cf. lanes 12,14,16, and 18). These results provide strong evidence that binding of Tat to the bulge is correlated functionally with trans-activation.

Next, we examined a mutant TAR RNA containing a 4-base substitution in the loop (TAR+31/+34). Although this mutation strongly reduced trans-activation activity in vivo (Roy et al. 1990), it did not significantly affect Tat binding in vitro (Fig. 5A, cf. lanes 20 and 22). Hence, the primary sequence in the loop is not required for Tat binding. These results indicate that Tat binding by itself is not sufficient to mediate trans-activation.

\section{The conformation of the bulge is important for Tat binding and trans-activation}

In addition to the primary sequence analysis of the bulge, we wished to examine the requirement for the bulge structure per se. To this end, we introduced mutations in the predicted duplex region of the stem-loop. Mutations included substitutions on either side of the stem and compensatory substitutions. SP6-derived tran-

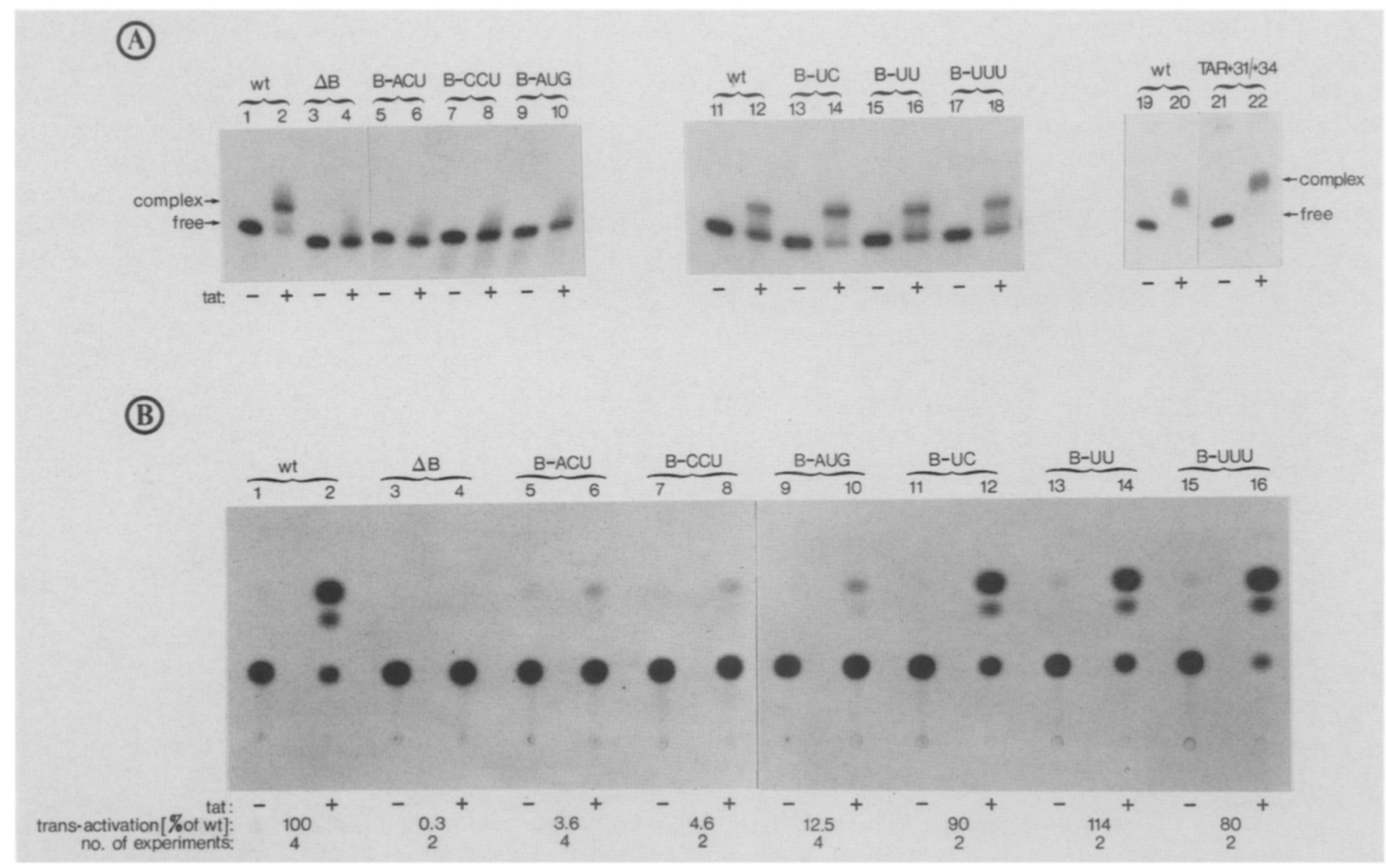

Figure 5. Effect of deletions and nucleotide substitutions in the bulge of TAR on Tat binding to TAR RNA in vitro and Tat-mediated trans-activation in vivo. (A) Tat binding to TAR RNA. Wild-type (wt) or mutant ${ }^{32}$ P-labeled TAR RNAs were incubated in the absence $(-)$ or presence $(+)$ of 100 (lanes 1-18) or 200 (lanes 19-22) ng of purified Tat and complexes were resolved on a nondenaturing polyacrylamide gel, as described in Experimental procedures. (B) Tat-mediated trans-activation. Wild-type (wt) or mutated pU3RIII was transfected into HeLa cells lacking (-) or stably expressing tat (+). Extracts were prepared $48 \mathrm{hr}$ after transfection. A representative CAT assay using $50 \mu \mathrm{g}$ of HeLa cell extract and $5 \mu \mathrm{g}$ of HeLa-tat cell extract is shown. The trans-activation activity was defined as the CAT activity obtained in the HeLa-tat cell line divided by that obtained in the parental cell line. Results, expressed as percent of wild-type (wt), represent an average of two to four independent experiments. 
scripts were tested in the RNA mobility-shift assay for binding to Tat. The first set of mutant RNAs are expected to distort (TAR III and TAR III') or restore (TAR III, III') the original bulge structure (Fig. 6, top). Mutants TAR III and TAR III', which were shown previously to have virtually no trans-activation activity in vivo (Roy et al. 1990), failed to form stable complexes with Tat (lanes 4 and 6). The double mutant TAR III, III', which was shown to restore TAR function to wild-type levels in vivo (Roy et al. 1990), bound to Tat albeit with some reduced efficiency (cf. lanes 8 and 2). Thus, proper conformation of the bulge structure (i.e., intact base-pairing between nucleotides +18 to +21 and +41 to +44 ) is required for Tat binding. The second set of mutant RNAs (TAR I, TAR I', and TAR I, I'), which are not expected to affect the bulge structure (Fig. 6, bottom), bound to Tat with similar efficiency as the wild-type RNA (cf. lanes 10, 12, 14, and 16). Disruption of basepairing in this region was shown previously to reduce trans-activation by 3- to 12-fold (TAR I: $31 \%$ of wildtype; TAR I': $8 \%$ of wild-type; Roy et al. 1990).

\section{A Tat peptide containing the basic domain binds specifically to TAR RNA}

To begin the analysis of the domain in Tat that interacts with TAR RNA, we tested a chemically synthesized Tat peptide comprising amino acids 38 to 62 in the RNA mobility-shift assay. This peptide was chosen because it contains a highly basic domain (amino acids 49 to 57) believed to be required for the interaction with nucleic acids. Significantly, this small peptide bound efficiently to TAR RNA (Fig. 7, lane 2). The specificity of the interaction was assessed by performing the assay with various mutant TAR RNAs. Mutants $\triangle B, B-A C U$, and B-CCU, which abrogate binding of the full-length wild-

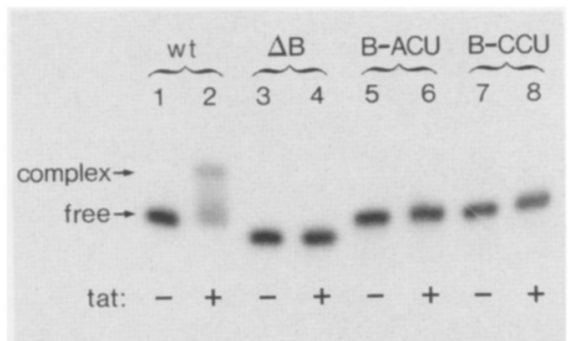

Figure 7. Electrophoretic mobility-shift analysis of a Tat peptide binding to TAR RNA. Wild-type (wt) (lanes 1 and 2) or mutant (lanes 3-8) ${ }^{32} \mathrm{P}$-labeled TAR RNAs were incubated in the absence $(-)$ or presence $(+)$ of $10 \mathrm{ng}$ of a chemically synthesized Tat peptide comprising amino acids 38 to 62 . The mobility-shift electrophoresis assay was performed essentially as described in Experimental procedures except that the peptide was preincubated with $15 \mathrm{ng}$ of tRNA, prior to the addition of 32P-labeled wild-type (lane 2) or mutant (lanes 4, 6, and 8) TAR RNAs. Nucleoprotein complexes were analyzed on a nondenaturing polyacrylamide gel, as described in Experimental procedures.

type protein, also failed to form nucleoprotein complexes with this peptide (lanes 4, 6, and 8). We further delimited the TAR-binding region to the basic domain inasmuch as a peptide comprising amino acids 47 to 58 was capable of binding with specificity to TAR RNA (data not shown).

\section{Discussion}

Our results strongly support a role for Tat binding to TAR RNA in the mechanism of trans-activation, and identify a critical nucleotide (uridine +23 ) in the 3-nucleotide bulge of TAR that is required for both Tat binding and trans-activation. In addition, our data sug-

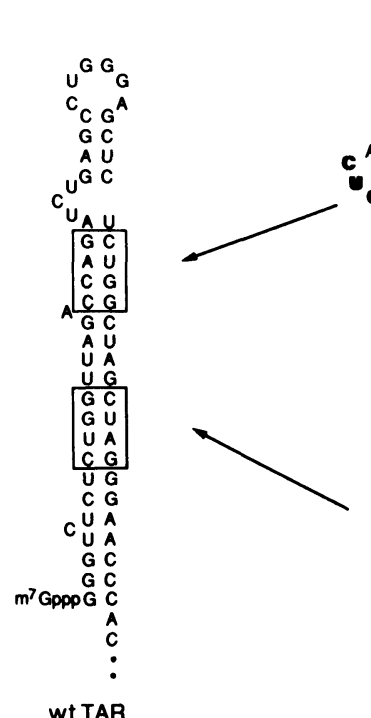

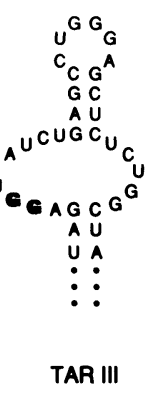

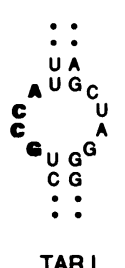

TAR I

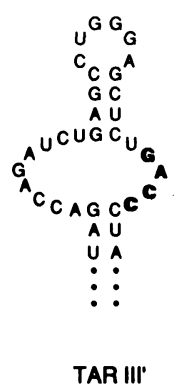

TAR III'

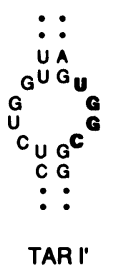

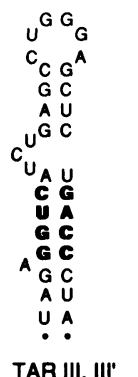

TAR III, III'

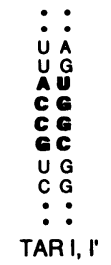

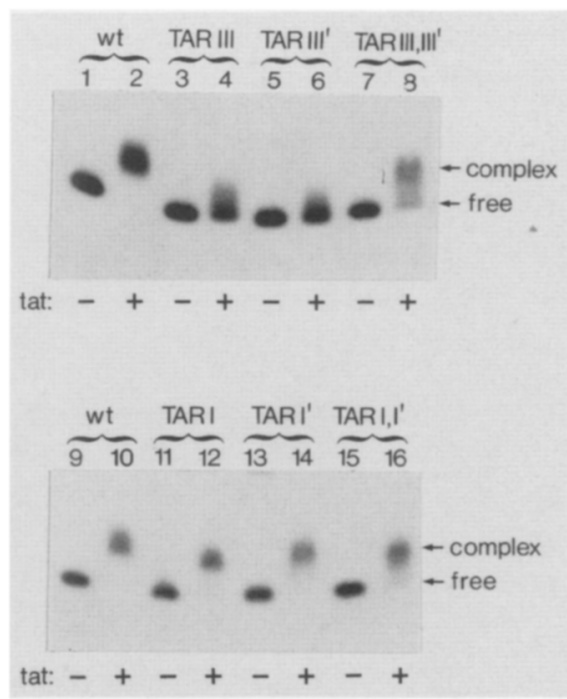

Figure 6. Effect of distorting the bulge structure on Tat binding in vitro. Mutations were introduced by site-directed mutagenesis as described in Experimental procedures. The predicted effect of base substitutions (indicated in boldface type) on the TAR stem-loop structure is shown. ${ }^{32} \mathrm{P}$-labeled wild-type $(w \mathrm{t})$ or mutant RNAs were mixed in the absence $(-)$ or presence $(+\mid$ of $200 \mathrm{ng}$ of purified Tat. Nucleoprotein complexes were analyzed on a nondenaturing polyacrylamide gel, as described in Experimental procedures. 
gest that the basic domain in Tat is responsible for the specific interaction with TAR RNA. This highly basic domain (8 lysine and arginine residues between amino acids 49 and 57) is required for Tat function in vivo and mediates subcellular localization of Tat to the nucleolus (Hauber et al. 1989; Kuppuswamy et al. 1989; Ruben et al. 1989|. These results suggest that nucleolar localization reflects the interaction of Tat with RNA.

The functional importance of the 3-nucleotide bulge in trans-activation has been shown before (Berkhout and Jeang 1989; Roy et al. 1990). Jakobovits et al. (1988) performed random mutagenesis in the TAR region and also found that a 3-base substitution in the bulge reduced trans-activation. The unique importance of the uridine base is in agreement with results of Berkhout and Jeang (1989) which show that base substitutions in the bulge reduced trans-activation to a greater extent when this uridine residue was changed to adenosine. Substitution of guanosine for this uridine residue also had a deleterious effect on both trans-activation and Tat binding (U. Delling, unpubl.). Moreover, this uridine residue at position +23 is highly conserved among different HIV-1, HIV-2, and SIV isolates although the rest of the sequence in the bulge is not. Interestingly, the TAR regions of HIV-2 and SIV, which have a bulge of 2 uridine residues in one of the proposed stem-loop structures (Arya 1988), are responsive to the Tat protein of HIV-1 (Emerman et al. 1987; Guyader et al. 1987; Arya 1988; Viglianti and Mullins 1988).

Notwithstanding the importance of Tat binding for trans-activation, it appears not to be sufficient to confer responsiveness to Tat in vivo. Indeed, a 4-base substitution in the loop, which was shown previously to reduce trans-activation activity drastically (Roy et al. 1990), did not affect Tat binding. Similarly, disrupting the integrity of the RNA secondary structure between nucleotides +9 to +12 and +49 to +52 perturbed TAR function in vivo (Roy et al. 1990), but not Tat binding in vitro. Dingwall et al. (1989) also found that the primary sequence in the loop is not required for nucleoprotein complex formation. These results imply that other trans-acting factors are required for trans-activation mediated by Tat. Consistent with this hypothesis, a number of cellular TAR RNA-binding proteins have been identified /Gatignol et al. 1989; Gaynor et al. 1989; Marciniak et al. 1990). TAR RNA-binding proteins from HeLa cell nuclear extracts with specificity for the loop sequence have recently been purified (Marciniak et al. 1990; R. Gaynor, pers. comm.). We also observed TAR RNA protein complexes with $\mathrm{HeLa}, \mathrm{CHO}$, and COS cell nuclear extracts, which were dependent on the integrity of the RNA stem structure between nucleotides +9 to +12 and +49 to +52 (S. Roy, unpubl.). The nature of these TAR RNAbinding proteins as well as their role in trans-activation remains to be determined.

Our results demonstrate that the target of Tat is RNA, thus substantiating the hypothesis that Tat-mediated trans-activation requires the recognition of the TAR region as RNA (Feng and Holland 1988; Berkhout et al. 1989). The mechanism of action of Tat probably in- volves transcriptional and post-transcriptional events. There is accumulating evidence that Tat increases the rate of transcription initiation (Jakobovits et al. 1988, Jeang et al. 1988; Rice and Mathews 1988; Laspia et al. 1989|. In this context, the TAR region could be acting as an RNA enhancer (Sharp and Marciniak 1989). Alternatively, Tat interaction with TAR may prevent premature termination of transcription (Kao et al. 1987; Selby et al. 1989; Toohey and Jones 1989). Support for post-transcriptional events as part of the mechanism of trans-activation was obtained recently from studies showing that translation of TAR-containing RNAs microinjected in the nuclei of Xenopus oocytes was stimulated by Tat (Braddock et al. 1989).

Bulged nucleotides within RNA stem-loop structures have been shown to be critical features for protein recognition. A bulged adenosine in the R17 coliphage operator is important for binding of the $\mathrm{R} 17$ coat protein (Romaniuk et al. 1987; Wu and Uhlenbeck 1987). A bulged cytosine in the iron-responsive element (IRE) within the $5^{\prime}$-untranslated region of the ferritin heavy chain mRNA is necessary for high affinity interactions with the $90-\mathrm{kD}$ IRE-binding protein (IRE-BP) (Haile et al. 1989). In addition, bulged adenosines are present in the 16S rRNA binding sites of ribosomal proteins S8 and S15 (Garrett et al. 1984). The trans-acting factor Rev of HIV-1, which is essential for the production of unspliced $(\sim 9 \mathrm{~kb})$ and singly spliced $(\sim 4 \mathrm{~kb})$ transcripts that encode viral structural proteins (for review, see Cullen and Greene 1989 and Pavlakis and Felber 1990), was recently reported to be an RNA-binding protein (Daly et al. 1989; Zapp and Green 1989; Cochrane et al. 1990; Heaphy et al. 1990). Its target, the Rev responsive element (RRE), forms a complex secondary structure (Dayton et al. 1989), that was shown to be necessary for both Rev binding in vitro and the Rev response in vivo (Malim et al. 1990; Olsen et al. 1990). Interestingly, a bulged nucleotide is present in one of the functionally important stem-loops. It remains to be determined whether this bulged nucleotide is required for Rev binding.

The identification of features within the TAR region and the Tat basic domain that are critical for Tat binding in vitro and TAR function in vivo should prove important for the elucidation of the mechanism of Tat-mediated trans-activation and might provide new strategies for the development of therapeutic approaches targeted against Tat.

\section{Experimental procedures}

Purification of Tat and production of monoclonal antibodies

A detailed description of the method used to purify biologically active Tat protein overexpressed in $E$. coli was presented elsewhere (Gentz et al. 1989). Splenocytes from mice immunized with purified $E$. coli overexpressed recombinant proteins Tat (Gentz et al. 1989) or Rev (Cochrane et al. 1989) were fused to myeloma cells using standard techniques (Harlow and Lane 1988). Hybridomas that tested positive by ELISA were cloned by limiting dilution. Monoclonal antibodies were purified from the ascites fluid using caprylic acid followed by ammonium sulfate precipitation (Harlow and Lane 1988). 


\section{Site-directed mutagenesis}

Mutations were introduced in the TAR region by oligonucleotide-directed mutagenesis in M13 by use of either the twoprimer method (Zoller and Smith, 1982) or an in vitro mutagenesis system (Amersham). The mutations were confirmed before and after subcloning in pSP64TARCAT (Parkin et al. 1988) and pU3RIII (Sodroski et al. 1985) by sequencing with the dideoxy chain-termination method (Sanger et al. 1977).

\section{Transfections and chloramphenicol acetyltransferase (CAT) assays}

HeLa and HeLa-tat cells (established as described by Rosen et al. $1986 \mathrm{~b}$ ) were plated at $1 \times 10^{6}$ cells in $10-\mathrm{cm}$ petri dishes one day before transfection. The DEAE-dextran method was used (Grosschedl and Baltimore 1985) with $5 \mu \mathrm{g}$ of DNA (pU3RIII constructs). After 40-48 hr, cells were harvested, and extracts were prepared by freeze-thawing 3 times, heating to $60^{\circ} \mathrm{C}$ for 7 min, and microfuging for $5 \mathrm{~min}$. Protein concentrations were determined by use of the Bradford colorimetric assay (Bio-Rad). CAT assays were performed with $50 \mu \mathrm{g}$ of HeLa cell extract and $5 \mu \mathrm{g}$ of HeLa-tat cell extract for $1 \mathrm{hr}$ at $37^{\circ} \mathrm{C}$ as described (Gorman et al. 1982). The percentage of acetylated ${ }^{14} \mathrm{C}$-chloramphenicol was determined by scintillation counting of the spots cut out from the TLC plate. Assays giving under $1 \%$ or over $70 \%$ acetylation were repeated with more or less extract. The fold trans-activation was defined as the CAT activity (corrected for the amount of protein used in the assay) obtained in HeLa-tat cells compared with that in the parental cells.

\section{In vitro transcriptions and RNA gel purification}

The SP64TARCAT constructs (Parkin et al. 1988) were linearized with HindIII (at nucleotide +80 in the HIV-1 sequence), phenol extracted, passed through a G-50 spin-column, and ethanol-precipitated. Uncapped SP6-derived transcripts were produced in the presence of $\left[\alpha^{-32}\right.$ P]UTP or GTP (New England Nuclear, $3000 \mathrm{Ci} / \mathrm{mmol}$ ), or $\left[5^{-3} \mathrm{H}\right] \mathrm{CTP}$ (New England Nuclear, 27 $\mathrm{Ci} / \mathrm{mmol}$ ), as described by Green et al. (1983). For mutants B-ACU, B-CCU, and B-UC, oligodeoxynucleotide templates for transcription by T7 RNA polymerase were synthesized and purified. Annealing of oligodeoxynucleotide templates and T7 transcriptions was carried out as described by Meerovitch et al. (1989), except that the GTP concentration was raised to 0.5 mM. RNAs were purified on $8 \%$ polyacrylamide- $8 \mathrm{M}$ urea gels, eluted in $0.5 \mathrm{M}$ ammonium acetate, $1 \mathrm{mM}$ EDTA, and $0.1 \%$ SDS (Grabowski et al. 1984), and recovered by two phenol extractions followed by ethanol precipitation.

\section{Mobility-shift electrophoresis assay}

The RNA mobility-shift assays were performed essentially according to Konarska and Sharp (1986). Briefly, 100-200 ng of purified Tat was preincubated in a buffer containing $10 \mathrm{~mm}$ Tris- $\mathrm{HCl}$ (pH 7.5), $1 \mathrm{~mm}$ DTT, $1 \mathrm{~mm}$ EDTA, $50 \mathrm{~mm} \mathrm{NaCl}, 0.5$ $\mathrm{U} / \mu \mathrm{l}$ RNasin, $0.09 \mu \mathrm{g} / \mu \mathrm{l}$ bovine serum albumin, and $0.05 \%$ (vol/vol) glycerol at $30^{\circ} \mathrm{C}$ for $10 \mathrm{~min}$. ${ }^{32} \mathrm{P}$-labeled RNA $(2000$ $\mathrm{cpm}, 2.94 \times 10^{6} \mathrm{cpm} / \mu \mathrm{g}$ ) was added for a further incubation of $10 \mathrm{~min}$. The final volume of the reaction was $20 \mu \mathrm{l}$. Samples were loaded on a $1.5-\mathrm{mm}$ thick, $5 \%$ polyacrylamide gel (30:0.8, acrylamide : bis-acrylamide) containing $5 \%$ glycerol, which had been preelectrophoresed for $30 \mathrm{~min}$ at $30 \mathrm{~mA}$. Electrophoresis was carried out in $0.5 \times \mathrm{TBE}$ at a constant current of $30 \mathrm{~mA}$ for $2.5 \mathrm{hr}$ at $4^{\circ} \mathrm{C}$. Gels were dried and exposed to X-ray film (Fuji) with intensifying screens at $-70^{\circ} \mathrm{C}$. Quantitations of complex formation were performed by scanning of X-ray films with an LKB soft laser densitometer.

\section{Acknowledgments}

We are grateful to Maria Jaramillo, Karen Meerovitch, and Charles Goyer for helpful comments and suggestions throughout the course of this work. We thank Martin SumnerSmith and Richard Barnett (Allelix Biopharmaceuticals) for providing us with the chemically synthesized Tat peptide and DNA templates for TAR RNA synthesis. This work was supported by grants from the American Foundation for AIDS Research (000946-7-RGR: AmFAR/Drexel Burnham Lambert Research Grant) and Cancer Research Society (Montréal) to N.S. N.S. is the recipient of a Medical Research Council Scientist award from the Medical Research Council of Canada. S.R. is a recipient of a studentship from the Fonds de Recherche en Santé du Québec, and U.D. is a recipient of a studentship from the Medical Research Council of Canada.

The publication costs of this article were defrayed in part by payment of page charges. This article must therefore be hereby marked "advertisement" in accordance with 18 USC section 1734 solely to indicate this fact.

\section{References}

Arya, S.K. 1988. Human and simian immunodeficiency retroviruses: activation and differential transactivation of gene expression. AIDS Res. Hum. Retrov. 4: 175-186.

Berkhout, B., and K.-T. Jeang. 1989. Trans-activation of human immunodeficiency virus type 1 is sequence specific for both the single-stranded bulge and loop of the trans-acting-responsive hairpin: a quantitative analysis. J. Virol. 63: 55015504.

Berkhout, B., R.H. Silverman, and K.-T. Jeang. 1989. Tat transactivates the human immunodeficiency virus through a nascent RNA target. Cell 59: 273-282.

Braddock, M., A. Chambers, W. Wilson, M.P. Esnouf, S.E. Adams, A.J. Kingsman, and S.M. Kingsman. 1989. HIV-1 tat "activates" presynthesized RNA in the nucleus. Cell 58: $269-279$.

Cochrane, A.W., C.-H. Chen, R. Kramer, L. Tomchak, and C.A. Rosen. 1989. Purification of biologically active human immunodeficiency virus rev protein from Escherichia coli. Virology 173: 335-337.

Cochrane, A.W., C.-H. Chen, and C.A. Rosen. 1990. Specific interaction of the human immunodeficiency virus Rev protein with a structured region in the env mRNA. Proc. Natl. Acad. Sci. 87: 1198-1202.

Cullen, B.R. 1986. Trans-activation of human immunodeficiency virus occurs via a bimodal mechanism. Cell 46: $973-$ 982.

Cullen, B.R. and W.C. Greene. 1989. Regulatory pathways governing HIV-1 replication. Cell 58: 423-426.

Daly, T.J., K.S. Cook, G.S. Gray, T.E. Maione, and J.R. Rusche. 1989. Specific binding of HIV-1 recombinant rev protein to the rev-responsive element in vitro. Nature 342: 816-819.

Dayton, A.I., J.G. Sodroski, C.A. Rosen, W.C. Goh, and W.A. Haseltine. 1986. The trans-activator gene of the human T cell lymphotropic virus type III is required for replication. Cell 44: 941-947.

Dayton, E.T., D.M. Powell, and A.I. Dayton. 1989. Functional analysis of CAR, the target sequence for rev protein of HIV-1. Science 246: 1625-1629.

Dingwall, C., I. Ernberg, M.J. Gait, S.M. Green, S. Heaphy, J. Karn, A.D. Lowe, M. Singh, M.A. Skinner, and R. Vallerio. 
1989. Human immunodeficiency virus 1 tat protein binds trans-activation responsive region (TAR) RNA in vitro. Proc. Natl. Acad. Sci. 86: 6925-6929.

Emerman, M., M. Guyader, L. Montagnier, D. Baltimore, and M.A. Muesing. 1987. The specificity of the human immunodeficiency virus type 2 trans-activator is different from that of human immunodeficiency virus type 1. EMBO $J$. 6: $3755-3760$.

Feinberg, M.B., R.F. Jarrett, A. Aldovini, R.C. Gallo, and F. Wong-Staal. 1986. HTLV-III expression and production involve complex regulation at the levels of splicing and translation of viral RNA. Cell 46: 807-817.

Feng, S. and E.C. Holland. 1988. HIV-1 tat trans-activation requires the loop sequence within tar. Nature 334: 165-167.

Fisher, A.G., M.B. Feinberg, S.F. Josephs, M.E. Harper, L.M. Marselle, G. Reyes, M.A. Gonda, A. Aldovini, C. Debouk, R.C. Gallo, and F. Wong-Staal. 1986. The trans-activator gene of HTLV-III is essential for virus replication. Nature 320: $367-371$.

Garcia, J.A., D. Harrich, E. Soultanakis, F. Wu, R. Mitsuyasu, and R.B. Gaynor. 1989. Human immunodeficiency virus type 1 LTR TATA and TAR region sequences required for transcriptional regulation. EMBO I. 8: 765-778.

Garrett, R.A., B. Vester, H. Leffers, P.M. Sorensen, J. Kjems, S.O. Olesen, A. Christensen, J. Christiansen, and S. Douthwaite. 1984. In Gene expression, (ed. B.F.C. Clark and H.U. Petersen/ pp. 331-376, Munksgaard, Copenhagen.

Gatignol, A., A. Kumar, A. Rabson, and K.-T. Jeang. 1989. Identification of cellular proteins that bind to the human immunodeficiency virus type 1 trans-activation-responsive $T A R$ element RNA. Proc. Natl. Acad. Sci. 86: 7828-7832.

Gaynor, R., E. Soultanakis, M. Kuwabara, J. Garcia, and D.S. Sigman. 1989. Specific binding of a HeLa cell nuclear protein to RNA sequences in the human immunodeficiency virus transactivating region. Proc. Natl. Acad. Sci. 86: $4858-4862$.

Gentz, R., C.-H. Chen, and C.A. Rosen. 1989. Bioassay for trans-activation using purified human immunodeficiency virus tat-encoded protein: Trans-activation requires mRNA synthesis. Proc. Natl. Acad. Sci. 86: 821-824.

Gorman, C.M., L.F. Moffat, and B.H. Howard. 1982. Recombinant genomes which express chloramphenicol acetyltransferase in mammalian cells. Mol. Cell. Biol. 2: 1044-1051.

Grabowski, P.J., R.A. Padgett, and P.A. Sharp. 1984. Messenger RNA splicing in vitro: an excised intervening sequence and a potential intermediate. Cell 37: 415-427.

Green, M.R., T. Maniatis, and D.A. Melton. 1983. Human $\beta$ globin pre-mRNA synthesized in vitro is accurately spliced in Xenopus oocyte nuclei. Cell 32: 681-694.

Grosschedl, R. and D. Baltimore. 1985. Cell type specificity of immunoglobulin gene expression is regulated by at least three DNA sequence elements. Cell 41: 885-897.

Guyader, M., M. Emerman, P. Sonigo, F. Clavel, L. Montagnier, and M. Alizon. 1987. Genome organization and transactivation of the human immunodeficiency virus type 2. Nature 326: 662-669.

Haile, D.J., M.W. Hentze, T.A. Rouault, J.B. Harford, and R.D. Klausner. 1989. Regulation of interaction of the iron-responsive element binding protein with iron-responsive RNA elements. Mol. Cell. Biol. 9: 5055-5061.

Harlow, E. and D. Lane. 1988. In Antibodies: A laboratory manual. Cold Spring Harbor Laboratory Press, Cold Spring Harbor New York.

Hauber, J. and B.R. Cullen. 1988. Mutational analysis of the trans-activation-responsive region of the human immunodeficiency virus type 1 long terminal repeat. J. Virol.
62: 673-679.

Hauber, J., M.H. Malim, and B.R. Cullen. 1989. Mutational analysis of the conserved basic domain of human immunodeficiency virus tat protein. J. Virol. 63: 1181-1187.

Heaphy, S., C. Dingwall, I. Ernberg, M.J. Gait, S.M. Green, J. Karn, A.D. Lowe, M. Singh, and M.A. Skinner. 1990. HIV-1 regulator of virion expression (rev) protein binds to an RNA stem-loop structure located within the rev response element region. Cell 60: 685-693.

Jakobovits, A., D.H. Smith, E.B. Jakobovits, and D.J. Capon. 1988. A discrete element 3' of human immunodeficiency virus 1 (HIV-1) and HIV-2 mRNA initiation sites mediates transcriptional activation by an HIV trans-activator. Mol. Cell. Biol. 8: 2555-2561.

Jeang, K.-T., P.R. Shank, and A. Kumar. 1988. Transcriptional activation of homologous viral long terminal repeats by the human immunodeficiency virus type 1 or the human T-cell leukemia virus type I tat proteins occurs in the absence of de novo protein synthesis. Proc. Natl. Acad. Sci. 85: 82918295.

Kao, S.-Y., A.F. Calman, P.A. Luciw, and B.M. Peterlin. 1987. Anti-termination of transcription within the long terminal repeat of HIV-1 by tat gene product. Nature 330: 489-493.

Konarska, M.M. and P.A. Sharp. 1986. Electrophoretic separation of complexes involved in the splicing of precursors to mRNAs. Cell 46: 845-855.

Kuppuswamy, M., T. Subramanian, A. Srinivasan, and G. Chinnadurai. 1989. Multiple functional domains of tat, the trans-activator of HIV-1, defined by mutational analysis. Nucleic Acids Res. 17: 3551-3561.

Laspia, M.F., A.P. Rice, and M.B. Mathews. 1989. HIV-1 tat protein increases transcriptional initiation and stabilizes elongation. Cell 59: 283-292.

Malim, M.H., L.S. Tiley, D.F. McCarn, J.R. Rusche, J. Hauber, and B.R. Cullen. 1990. HIV-1 structural gene expression requires binding of the rev trans-activator to its RNA target sequence. Cell 60: 675-683.

Marciniak, R.A., M.A. Garcia-Blanco, and P.A. Sharp. 1990. Identification and characterization of a HeLa nuclear protein that specifically binds to the trans-activation-response (TAR) element of human immunodeficiency virus. Proc. Natl. Acad. Sci. 87: 3624-3628.

Meerovitch, K., J. Pelletier, and N. Sonenberg. 1989. A cellular protein that binds to the $5^{\prime}$-noncoding region of poliovirus RNA: implications for internal translation initiation. Genes Dev. 3: 1026-1034.

Muesing, M.A., D.H. Smith, and D.J. Capon. 1987. Regulation of mRNA accumulation by a human immunodeficiency virus trans-activator protein. Cell 48: 691-701.

Myers, G. 1989. Human retroviruses and AIDS. A compilation and analysis of nucleic acid and amino acid sequences. Los Alamos, Los Alamos National Laboratory.

Olsen, H.S., P. Nelbock, A.W. Cochrane, and C.A. Rosen. 1990. Secondary structure is the major determinant for interaction of HIV rev protein with RNA. Science 247: 845-848.

Parkin, N.T., E.A. Cohen, A. Darveau, C. Rosen, W. Haseltine, and N. Sonenberg. 1988. Mutational analysis of the $5^{\prime}$ noncoding region of human immunodeficiency virus type 1: effects of secondary structure on translation. EMBO $J$. 7: $2831-2837$.

Pavlakis, G.N. and B.K. Felber. 1990. Regulation of expression of human immunodeficiency virus. The New Biologist 2: 20-31.

Peattie, D.A., S. Douthwaite, R.A. Garrett, and H.F. Noller. 1981. A "bulged" double helix in a RNA-protein contact site. Proc. Nat1. Acad. Sci. 78: 7331-7335. 
Rice, A.P. and M.B. Mathews. 1988. Transcriptional but not translational regulation of HIV-1 by the tat gene product. Nature 332: 551-553.

Romaniuk., P.J., P. Lowary, H.N. Wu, G. Stormo, and O.C. Uhlenbeck. 1987. RNA binding site of R17 coat protein. Biochemistry 26: 1563-1568.

Rosen, C.A., J.G. Sodroski, and W.A. Haseltine. 1985. The location of cis-acting regulatory sequences in the human $\mathrm{T}$ cell lymphotropic virus type III (HTLV-III/LAV) long terminal repeat. Cell 41: 813-823.

Rosen, C.A., J.G. Sodroski, W.C. Goh, A.I. Dayton, J. Lippke, and W.A Haseltine. 1986a. Post-transciptional regulation accounts for the trans-activation of the human T-lymphotropic virus type III. Nature 319: 555-559.

Rosen, C.A., J.G. Sodroski, K. Campbell, and W.A. Haseltine. 1986b. Construction of recombinant murine retroviruses that express the human T-cell leukemia virus type II and human T-cell lymphotropic virus type III trans-activator genes. I. Virol. 57: 379-384.

Roy, S., N.T. Parkin, C. Rosen, J. Itovitch, and N. Sonenberg. 1990. Structural requirements for trans-activation of human immunodeficiency virus type 1 long terminal repeat-directed gene expression by tat: Importance of base pairing, loop sequence, and bulges in the tat-responsive sequence. $J$. Virol. 64: 1402-1406.

Ruben, S., A. Perkins, R. Purcell, K. Joung, R. Sia, R. Burghoff, W.A. Haseltine, and C.A. Rosen. 1989. Structural and functional characterization of human immunodeficiency virus tat protein. J. Virol. 63: 1-8.

Sadaie, M.R., T. Benter, and F. Wong-Staal. 1988. Site-directed mutagenesis of two trans-regulatory genes (tat-III, trs) of HIV-1. Science 239: 910-913.

Sanger, F., S. Nicklen, and A.R. Coulson. 1977. DNA sequencing with chain-terminating inhibitors. Proc. Natl. Acad. Sci. 74: 5463-5467.

Selby, M.J., E.S. Bain, P.A. Luciw, and B.M. Peterlin. 1989. Structure, sequence, and position of the stem-loop in tar determine transcriptional elongation by tat through the HIV-1 long terminal repeat. Genes Dev. 3: 547-558.

Sharp, P.A. and R.A. Marciniak. 1989. HIV TAR: an RNA enhancer? Cell 59: 229-230.

Sodroski, J., C. Rosen, F. Wong-Staal, S.Z. Salahuddin, M. Popovic, S. Arya, R.C. Gallo, and W.A. Haseltine. 1985. Transacting transcriptional regulation of human T-cell leukemia virus type III long terminal repeat. Science 227: 171-173.

Toohey, M.G. and K.A. Jones. 1989. In vitro formation of short RNA polymerase II transcripts that terminate within the HIV-1 and HIV-2 promoter-proximal downstream regions. Genes Dev. 3: 265-282.

Viglianti, G.A. and J.I. Mullins. 1988. Functional comparison of transactivation by simian immunodeficiency virus from rhesus macaques and human immunodeficiency virus type 1. J. Virol. 62: 4523-4532.

Wickens, M.P. and J.E. Dahlberg. 1987. RNA-protein interactions. Cell 51: 339-342.

Wright, C.M., B.K. Felber, H. Paskalis, and G.N. Pavlakis. 1986. Expression and characterization of the trans-activator of HTLV-III/LAV virus. Science 234: 988-992.

Wu, H.N. and O.C. Uhlenbeck. 1987. Role of a bulged A residue in a specific RNA-protein interaction. Biochemistry 26: $8221-8227$.

Zapp, M.L. and M.R. Green. 1989. Sequence-specific RNA binding by the HIV-1 rev protein. Nature 342: 714-716.

Zoller, M.J. and M. Smith. 1982. Oligonucleotide-directed mutagenesis using M13-derived vectors: an efficient and general procedure for the production of point mutations in any fragment of DNA. Nucleic Acids Res. 10: 6487-6500. 


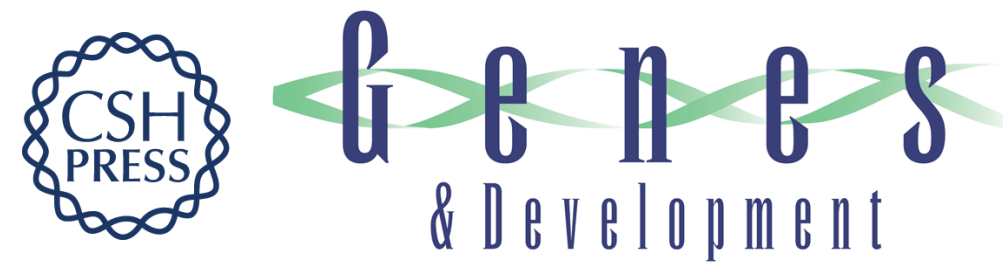

\section{A bulge structure in HIV-1 TAR RNA is required for Tat binding and Tat-mediated trans-activation.}

S Roy, U Delling, C H Chen, et al.

Genes Dev. 1990, 4:

Access the most recent version at doi:10.1101/gad.4.8.1365

References This article cites 61 articles, 25 of which can be accessed free at: http://genesdev.cshlp.org/content/4/8/1365.full.htmI\#ref-list-1

License

Email Alerting

Receive free email alerts when new articles cite this article - sign up in the box at the top Service right corner of the article or click here.

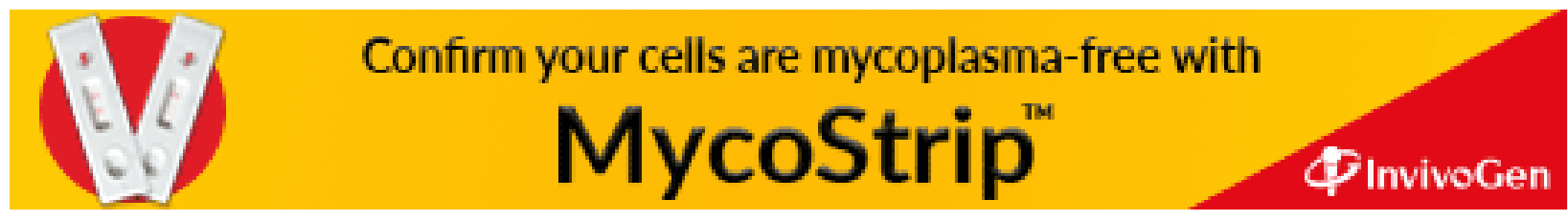

